\title{
Seasonal performance assessment of a Dual Source Heat Pump system for heating, cooling and domestic hot water production
}

\author{
Antonio Cazorla-Marín Carla Montagud \\ Javier Marchante-Avellaneda
}

\author{
José M. Corberán
}

\begin{abstract}
In order to contribute to a global $\mathrm{CO}_{2}$ emissions reduction in 2020, the increase in the use of highly efficient heat pumps for heating, cooling and domestic hot water production in buildings is very recommendable. In this direction, Ground Source Heat Pump (GSHP) systems are generally recognized as one of the most energy-efficient compared to air source heat pump systems. However, this strongly depends on the temperature evolution of the air and the ground during the year, which also depends on the geographical location of the system. Therefore, an optimal system from the energy point of view apparently would be the one that is able to switch from one source to the other in order to operate the beat pump with the highest efficiency.

In this context, a new Dual Source Heat Pump (DSHP) unit for heating, cooling and production of domestic hot water, was developed and manufactured in the framework of a H2020 European project called GEOTECH (Geothermal Technology for €conomic Cooling and Heating). This paper presents the assessment of such a DSHP in different representative locations around Europe. For this purpose, an integrated system model in TRNSYS was developed to assess its performance for different thermal demand profiles obtained for the same building under different conditions.
\end{abstract}

\section{INTRODUCTION}

Achieving Europe's 2020 and 2050 targets on greenhouse gas emissions, will not only require a reduction in the energy demand, but also a more efficient energy use and a higher contribution of renewable energy technologies (European Technology Platform on Renewable Heating and Cooling 2013). Looking at the final global energy use, buildings are responsible for almost a third of the total amount (IEA 2011), becoming a very important source of $\mathrm{CO}_{2}$ emissions. Particularly, in the European Union, buildings account for $40 \%$ of total energy use; and fairly half of this energy use corresponds to heating and cooling systems. Therefore, the introduction of highly efficient, reliable and affordable renewable heating and cooling systems in Europe becomes key to achieve on time the European Union's energy and climate objectives. This will mean the first step for a future decarbonisation in Europe. Ground source heat pump (GSHP) systems could positively contribute to this objective, as they are a renewable and efficient alternative to other conventional systems such as boilers that still imply the use of fossil fuels. However, they are still not competitive in terms of cost, especially in the South of Europe where the market of GSHP systems has not taken off yet. A strong 
effort was made during the last years in order to improve their cost effectiveness. One of the most commonly used solutions consists of combining different types of sources into a hybrid energy system. An example can be found in the Geot€ch project 'GEOthermal Technology for economic Cooling and Heating' (European Commision 2015), a four year's duration project funded by the European commission within the H2020 program. One of the aims of the Geot€ch project is to develop system solutions that make the best use of hybrid heat pump and control technologies so that efficient replicable and comparative low cost "plug and play" whole systems for heating, cooling and domestic hot water (DHW), can be offered to the housing and small building market sectors. One of the core components of such 'plug and play' systems consists of an innovative dual source heat pump (DSHP), which is capable of making optimal use of ground or air environmental heat sources according to operating and climate conditions. For instance, it could happen that the air is a more advantageous source for the production of domestic hot water during the summer compared to the ground. Analogously, at the end of the winter after a long heat extraction period from the ground, the daily variation of the air temperature could make it more advantageous as a source compared to the ground. This innovative DSHP is a variable capacity (inverter compressor) reversible heat pump operating with R32 as refrigerant, with a nominal heating capacity of $8 \mathrm{~kW}$ and a constructive solution 'plug\&play'. Further details of the heat pump design and operation can be found in (Corberán, et al. 2018). Thanks to the use of this innovative heat pump and the development of appropriate control strategies, not only the seasonal performance can be optimized but also the final cost of the installation can be reduced due to a lower amount of heat exchanged with the ground source heat exchanger (GSHE), and thus the need for less boreholes, reducing the investment cost significantly. This was highlighted in (Corberán, et al. 2018), where a first energy assessment was carried out for an office building located in the Netherlands. Results proved that the DSHP system would be able to reach a similar efficiency than the same unit operating as a GSHP, with half the ground source heat exchanger area needed, leading to a reduction in the investment cost up to 30\%. This paper presents the energy assessment of the DSHP integrated system for heating, cooling and DHW production in an institutional type of building existing at the Universitat Politècnica de València, in Spain, which was constructed in the 1970s. This specific building was compeletely modelled in TRNSYS and validated against experimental data as a part of a GSHP system model of an existing installation that provides heating and cooling to several offices inside the building (Ruiz-Calvo, et al. 2017). The existing GSHP installation was built in the framework of the GeoCool project (European Commision 2003) and it was refurbished and optimized in the framework of the Ground-Med project (European Commision 2009). This is the main reason why it was the building considered for the energy assessement presented in this study. However, it should be noted that the DSHP analyzed is meant not only for renovation but also for new buildings. In order to carry out the assessment of such a DSHP system for the same type of building in different representative locations around Europe, the European regulation EU Reg. 811/2013 for energy labelling of space heaters, was considered. In such regulation, three reference locations are identified for colder, average and warmer climate conditions: Helsinki (Finland), Strasbourg (France) and Athens (Greece) respectively.However, the thermal demand of the building is not only affected by the climate conditions but also by the type of construction considered which is also influenced not only by the location but also by the age of the building. In order to account for this in the TRNSYS simulations carried out for the assessment, the building typology data base from the IEE European Project TABULA (Typology Approach for Building Stock Energy Assessment) (IEE 2009a) was considered for each of the representative locations considered in the energy assessment. This data base includes different building typologies for 13 European countries. Each national typology consists of a classification scheme grouping buildings according to their size, age and further parameters and a set of exemplary buildings representing the building types.

\section{METHODOLOGY}

\section{Integrated system model in TRNSYS}

A complete dynamic model was developed in TRNSYS. The model includes all the integrated system components: building thermal load, heat pump, ground loop including the GSHE, space heating and cooling (User 
loop) and DHW hydraulic loops, all with their respective components such as pipes, circulation pumps, buffer tank and DHW tank. In order to model the control and operation of the system, a PID was included to set the frequency of the heat pump compressor, as well as other controllers to vary the frequency of the circulation pumps, and to control the temperature setpoint and on/off of the heat pump). A previous stage of this model was presented and analysed in (Corberán, et al. 2017) and (Ruiz-Calvo, et al. 2017). The model was prepared in a modular way, so that it allowed modifiying and adapting the components to different installations, as well as easily testing different optimization and control strategies. Regarding the heat pump, it consists of the innovative DSHP developed in the Geot€ch project. The DSHP system is capable of operating in eleven different operating modes, which are presented in Table 1.

Table 1. Heat pump and system operating modes (Corberán, et al. 2017)

\begin{tabular}{cccc}
\hline & Condenser & Evaporator & Operating mode \\
\hline \hline \multirow{2}{*}{ SUMMER } & Air & User & M1-Summer Air \\
& Ground & User & M2-Summer Ground \\
& -- & -- & M10-Free cooling \\
& DHW & User & M3-DHW User \\
& DHW & Air & M6-DHW Air \\
DHW & Ground & M8-DHW Ground \\
& DHW & Air & M11-Free-cooling + DHW Air \\
\hline User & Air & M4-Winter Air \\
& User & Ground & M5-Winter Ground \\
DHW & Air & M7-DHW Air \\
DHW & Ground & M9-DHW Ground \\
\hline
\end{tabular}

As shown in Table 1, the DSHP is able to provide heating, cooling and DHW using two different sources (air or ground). Furthermore, when the return temperature from the ground loop is low enough to meet the thermal cooling demand, the system is able to work in free-cooling mode. For that purpose, the system includes an extra free-cooling heat exchanger. Additionally, in summer operating conditions, the DHSP is able to use the waste heat in the condenser to heat up the water in the DHW tank. This happens when there is both the need of cooling and DHW production and the operating mode M3-DHW User is used. This operating mode is also called by the DSHP manufacturer 'Full Recovery' operating mode. The DSHP was experimentally tested in the framework of the Geot€ch project under the different operating modes shown in Table 1. As the heat pump is the core of the system, a very accurate model is needed in order to make a fair assessment of its performance. Therefore, the authors decided to make their own TRNSYS type for modelling the heat pump. This way, the heat pump was modelled as a black box with polynomial correlations able to reproduce the heat pump performance under different operating conditions. It will depend not only on the source and load inlet temperature ( $T e_{i}$ and $T c_{i}$, for the evaporator and condenser, respectively), but also on many other operating variables, such as the compressor frequency $\left(f_{\text {comp }}\right)$, temperature difference in each heat exchanger $(d T e$ and $d T c)$ and fan frequency $\left(f_{\text {fan }}\right)$. The correlations were tuned to experimental measurements and the influence of the variation of each operating variable was modelled with a maximum deviation of $5 \%$. A detailed explanation of the DSHP model can be found in (Corberán, et al. 2017). Equations (1)-(3) provide the heat pump performance for the Winter Ground operating mode (M5), where $\dot{Q}_{c o n d}$ is the condenser capacity, $\dot{Q}_{\text {evap }}$ is the evaporator capacity, and $\dot{W}_{\text {comp }}$ is the compressor power input.

$$
\begin{aligned}
& \dot{Q}_{\text {cond }}=f_{\text {comp }} \cdot\left(C_{0}+C_{1} \cdot T e_{i}+C_{2} \cdot T c_{i}+C_{3} \cdot T e_{i} \cdot T c_{i}+C_{4} \cdot T e_{i}^{2}+C_{5} \cdot d T e+C_{6} \cdot d T c+C_{7} \cdot T e_{i}\right. \\
& \left.\cdot d T e+C_{8} \cdot T c_{i} \cdot d T c\right) \\
& \dot{Q}_{\text {evap }}=f_{\text {comp }} \cdot\left(C_{0}+C_{1} \cdot T e_{i}+C_{2} \cdot T c_{i}+C_{3} \cdot T e_{i} \cdot T c_{i}+C_{4} \cdot T e_{i}^{2}+C_{5} \cdot d T e+C_{6} \cdot d T c+C_{7} \cdot T e_{i}\right. \\
& \left.\cdot d T e+C_{8} \cdot T c_{i} \cdot d T c\right)
\end{aligned}
$$




$$
\begin{aligned}
\dot{W}_{\text {comp }}=f_{\text {comp }} \cdot & \left(C_{0}+C_{1} \cdot T e_{i}^{2}+C_{2} \cdot T c_{i}^{2}+C_{3} \cdot d T e+C_{4} \cdot d T c+C_{5} \cdot T e_{i} \cdot d T e+C_{6} \cdot f_{\text {comp }} \cdot T e_{i}+C_{7}\right. \\
& \left.\cdot f_{\text {comp }} \cdot T c_{i}+C_{8} \cdot f_{\text {comp }}^{2} \cdot T e_{i} \cdot T c_{i}+C_{9} \cdot f_{\text {comp }} \cdot d T e+C_{10} \cdot \frac{1}{f_{\text {comp }}}\right)
\end{aligned}
$$

When the heat pump is operating with the air, the same polynomials were found to be adequate with the substitution of the temperature difference in the source heat exchanger, which is related to the brine flow rate in the ground mode, by the fan frequency.

\section{Selection of the source/sink}

In order to increase the seasonal performance of the system, it is key that the heat pump works under the most favourable conditions (air or ground source). For this purpose, a differential controller with hysteresis was implemented also to provide it with a stable type of control. Figure 1 shows this selection of the most favourable source (the colder in cooling mode and the hotter in heating and DHW mode).

a) Heating mode

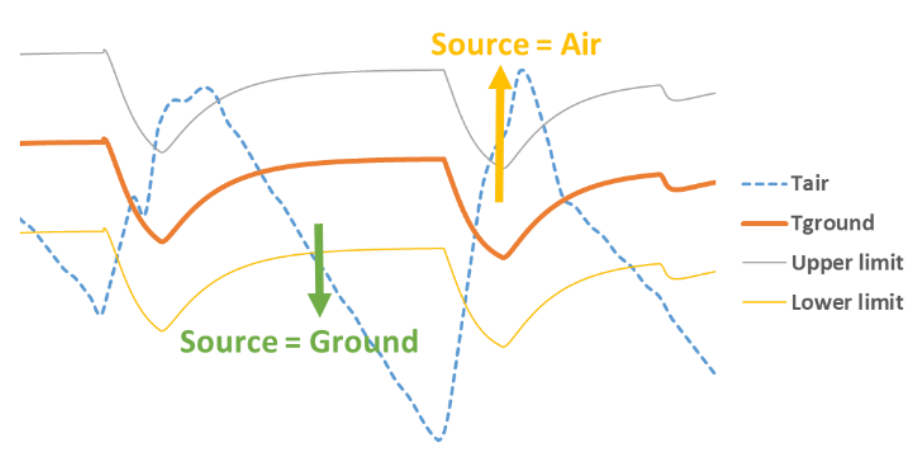

b) Cooling mode

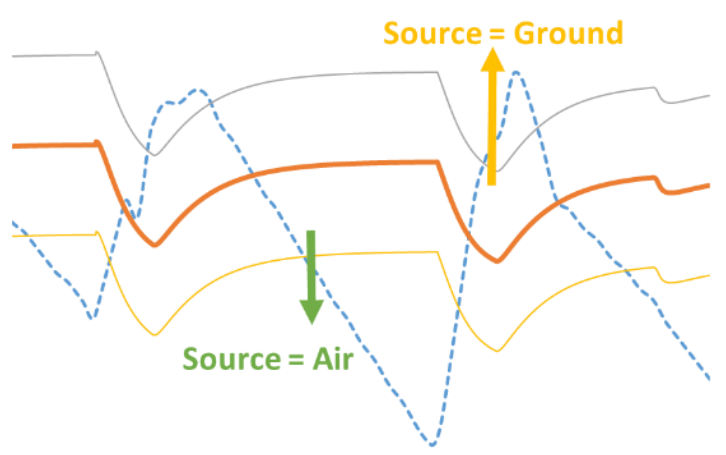

Figure 1 Selection of the source depending on the air and ground temperature: a) heating mode; b) cooling mode.

\section{System performance indicators}

The Seasonal Performance Factor (SPF) of the system was considered as the energy performance indicator for the energy assessment. The definition considered is the same as the one identified as SPF4 in the SEPEMO-build "SEasonal PErformance factor and MOnitoring for heat pump systems in the building sector" project (IEE 2009b).

$$
S P F 4=\frac{\int_{0}^{t}\left(\dot{Q}_{U S E R}+\dot{Q}_{D H W}\right) \cdot d t}{\int_{0}^{t}\left(\dot{W}_{H P}+\dot{W}_{F A N}+\dot{W}_{B H E}+\dot{W}_{B A C K U P}+\dot{W}_{U S E R}+\dot{W}_{D H W}\right) \cdot d t}
$$

where $\dot{Q}$ is the useful heat in the user loop $\left(\dot{Q}_{U S E R}\right)$ or DHW loop $\left(\dot{Q}_{D H W}\right)$, and $\dot{W}$ is the power consumption of each of the components existing in the system (heat pump $\dot{W}_{H P}$, fan $\dot{W}_{F A N}$, borehole heat exchanger (BHE) circulation pump $\dot{W}_{B H E}$, user circulation pump $\dot{W}_{U S E R}$ and DHW circulation pump $\dot{W}_{D H W}$ ), including the back-up system electrical consumption $\dot{W}_{B A C K U P}$ in case that there is any. The energy assessment will be carried out for one year of operation. So, the integration period will correspond to one year. Additionally, and in order to compare the use of the ground/air under different conditions, the amount of thermal energy provided by the heat pump in the different operating modes will be calculated. 


\section{System assessment in different locations}

\section{Building typology and thermal load calculation.}

The thermal demand to be met by the system is modeled as a thermal load profile based on the building of the Applied Thermodynamics department of the Universitat Politècnica de València, in Spain. The building was built in the 70 's. The air conditioned area $\left(250 \mathrm{~m}^{2}\right.$ in total) corresponds to some of the department offices located on the second floor of the building. In order to compare the DSHP system operating under different climatological conditions, the thermal demand of this building has specifically been calculated for three different locations in Europe: Stockholm (Sweden), Strasbourg (France) and Athens (Greece) for the same type of building modelled in TRNSYS. These three locations were selected in order to follow the European regulation EU Reg. 811/2013 for energy labelling of space heaters. However, no data was available for Finland in the TABULA project. Alternatively, building construction information was found for Sweden. So, the authors decided to select Stockholm as the European city that stands for 'colder' climate conditions instead of Helsinki which is the city identified in the EU Reg. 811/2013. The reason for selecting Stockholm is that Sweden is a bordering country of Finland and the climate conditions are similar: the maximum, minimum and average temperatures in Helsinki are $24^{\circ} \mathrm{C},-21^{\circ} \mathrm{C}$ and $4.7^{\circ} \mathrm{C}$, respectively, while in the case of Stockholm, they are $28^{\circ} \mathrm{C},-20^{\circ} \mathrm{C}$ and $5.3^{\circ} \mathrm{C}$. Thanks to the building typology webtool provided by the TABULA project, it was possible to check the global heat transfer coefficient per unit area $\left(\mathrm{U}\right.$ value expressed in $\left(\mathrm{W} /\left(\mathrm{m}^{2} \cdot \mathrm{K}\right)\right)$ for the same type of building and the same construction year, in the three different European cities selected. According to the nomenclature used in the TABULA project data base, these $U$ values were checked for the case of the existing building located in Valencia (Spain) and constructed in the 70's. It was found that they corresponded to a wall type Wall 1 (existing state) and a window type Window 1(usual refurbishment). Therefore, the $\mathrm{U}$ values considered correspond to Wall 1 and Window 1 type respectively for each one of the three cities identified in this study. Table 2 shows these values both for the building's envelope and the windows. As previously stated, the building considered in this study was previously modelled in TRNSYS, based on real data of occupancy, as a part of a GSHP system model of an existing installation with a total surface of around $250 \mathrm{~m}^{2}$. The heating capacity of the installed heat pump is around $17 \mathrm{~kW}$ so, in order to adapt the thermal demand to the nominal capacity of the DSHP $(8 \mathrm{~kW})$ analysed in this research work for the different types of locations, only a 30\% of the surface of the offices (around $75 \mathrm{~m}^{2}$ ) was considered. Then, in order to account for the different types of construction existing in each location for the same type and same age of building, the U value of the building's envelope and windows were introduced in the building TRNSYS model, keeping the rest of the building parameters constant. The TRNSYS building model, adapted to the different locations by changing the U-values, was simulated for a whole year under the corresponding weather conditions, obtaining the required thermal loads in order to maintain the comfort conditions inside the conditioned area. Table 2 shows the peak heating and cooling demand of the whole year, together with the seasonal and yearly thermal demand required. Finally, the climatic weather data was considered for each different city extracted from the weather database Meteonorm (Meteotest 1981) and simulated in TRNSYS for a year. Table 3 shows the maximum, minimum and average ambient temperatures for each city considered in the study.

Table 2. Thermal parameters in the different locations

\begin{tabular}{cccc}
\hline Location & Athens & Strasbourg & Stockholm \\
\hline \hline U building envelope/windows $\left(\mathrm{W} / \mathrm{m}^{2} \mathrm{~K}\right)$ & $2.2 / 3.20$ & $0.78 / 1.40$ & $0.41 / 0.9$ \\
Peak heating/cooling $(\mathrm{kW})$ & $6.1 / 4.8$ & $9.2 / 2.1$ & $11.7 / 0$ \\
Heating/cooling demand $(\mathrm{kWh})$ & $3565 / 3262$ & $7766 / 514$ & $11491 / 0$ \\
Yearly thermal demand $(\mathrm{kWh})$ & 6827 & 8280 & 11491 \\
Summer period & $02 / 05-22 / 10$ & $18 / 06-10 / 09$ & - \\
\hline
\end{tabular}

Moreover, another parameter that is specific for each city and that will affect the performance of the installation is the 
type of soil. Table 3 shows the main thermal properties of the soil that will affect the ground source heat exchanger performance in each location.

Table 3. Locations parameters

\begin{tabular}{cccc}
\hline Location & Athens & Strasbourg & Stockholm \\
\hline \hline Maximum/Minimum/Average ambient temperature $\left({ }^{\circ} \mathrm{C}\right)$ & $38 / 0 / 17.6$ & $32 /(-11) / 9.8$ & $28 /(-20) / 5.3$ \\
Ground thermal conductivity $(\mathrm{W} /(\mathrm{m} \cdot \mathrm{K}))$ & 3.75 & 1 & 3.75 \\
Ground volumetric thermal capacitance $\left(\mathrm{kJ} /\left(\mathrm{m}^{3} \cdot \mathrm{K}\right)\right)$ & 1250 & 1250 & 1250 \\
\hline
\end{tabular}

The values of the ground thermal properties appearing in Table 3 were obtained as a result of the work carried out in the framework of the GEOT€CH project (Tinti, et al. 2018), considering the thickness of the sediment layers existing in each location and the thermal properties of sediments and bedrock.

Operation parameters. The DSHP system performance has been analysed for three cities in Europe: Strasbourg (average climate), Athens (warmer climate) and Stockholm (colder climate). For this purpose, the integrated system model in TRNSYS has been adapted to the different locations, but keeping the same installation. Therefore, all the components and the main control parameters of the systems are the same for the three locations:

- Schedules: building climate conditioning: from 6 a.m. to 10 p.m., DHW production: 4 a.m. to 6 a.m.

- Comfort temperature in the offices: $23^{\circ} \mathrm{C}$, both for heating and cooling.

- Occupancy of the building, based on the real schedule of the professors that work in the offices.

- DHW demand: profile corresponding to an office of five people (equivalent to the occupancy of those five offices considered for the calculation of the thermal demand of the building).

- BHEs field: Four coaxial BHEs, 50 meters deep each. The borehole field was dimensioned for that location with the highest thermal load and it was kept the same for the three locations.

- Same components size: heat pump (nominal capacity $8 \mathrm{~kW}$ ), hydraulic loops, buffer tank (150 litres), DHW tank (300 litres), circulation pumps.

- The temperature of the water supply is a function of the annual average ambient temperature: $20 \%$ larger in summer conditions and $20 \%$ lower in winter conditions.

In addition, the main parameters of the system that will vary from one location to the other are the thermal load profile, the heating (winter) and cooling (summer) period, the ambient temperature and the ground thermal properties, due to differences in the climatological and geological conditions of the locations. These main differences are summarized in Table 2 and Table 3.

\section{ASSESSMENT RESULTS}

In order to assess the behavior of the DSHP system operating under different climatic conditions, the integrated system model in TRNSYS has been adapted to the three cities (Athens, Strasbourg and Stockholm). For this purpose, the thermal demand of the building in each location has been considered, as well as the climatic and geological characteristics of each site, summarized in Table 2 and Table3. An annual simulation was carried out for each location, with a time step of 1 minute. The total thermal energy provided by the system was calculated for each operating mode, as well as the SPF4. Figure 2 shows the thermal energy provided by the heat pump in each different operating mode as a percentage of the total energy provided by the heat pump all over the year for every location. The total thermal energy provided by the heat pump in each location is shown in Table 4 for building climate conditioning (M1-M5 and M10), and DHW production (M6-M9). From Figure 2, it can be extracted that the most used source/sink in Athens is the ground $(95 \%)$. Due to the warm climate, the ground is most of the time more favourable for providing both heating and cooling to the building, because the ground temperature is closer to the comfort temperature (average return temperature from the ground is $17.8^{\circ} \mathrm{C}$ ) than the air temperature. Here, the use of the heat pump for providing heating and cooling is quite balanced ( $51 \%$ of heating and $43 \%$ of cooling of the total energy provided), compared to the other 
locations, where the heating is the prevailing operating mode. Regarding Strasbourg, it has a very low cooling demand, and it can be met by the free-cooling loop ( $6 \%$ of the total energy), this happens due to the mild summer and the low return temperatures from the ground. The energy provided using the air as a source is the $27 \%$ of the total energy. In the case of Stockholm, as it has no cooling demand, all the energy provided by the heat pump is used to provide heating and DHW during the winter, and only DHW during the summer. The most used source is the ground (78\%).

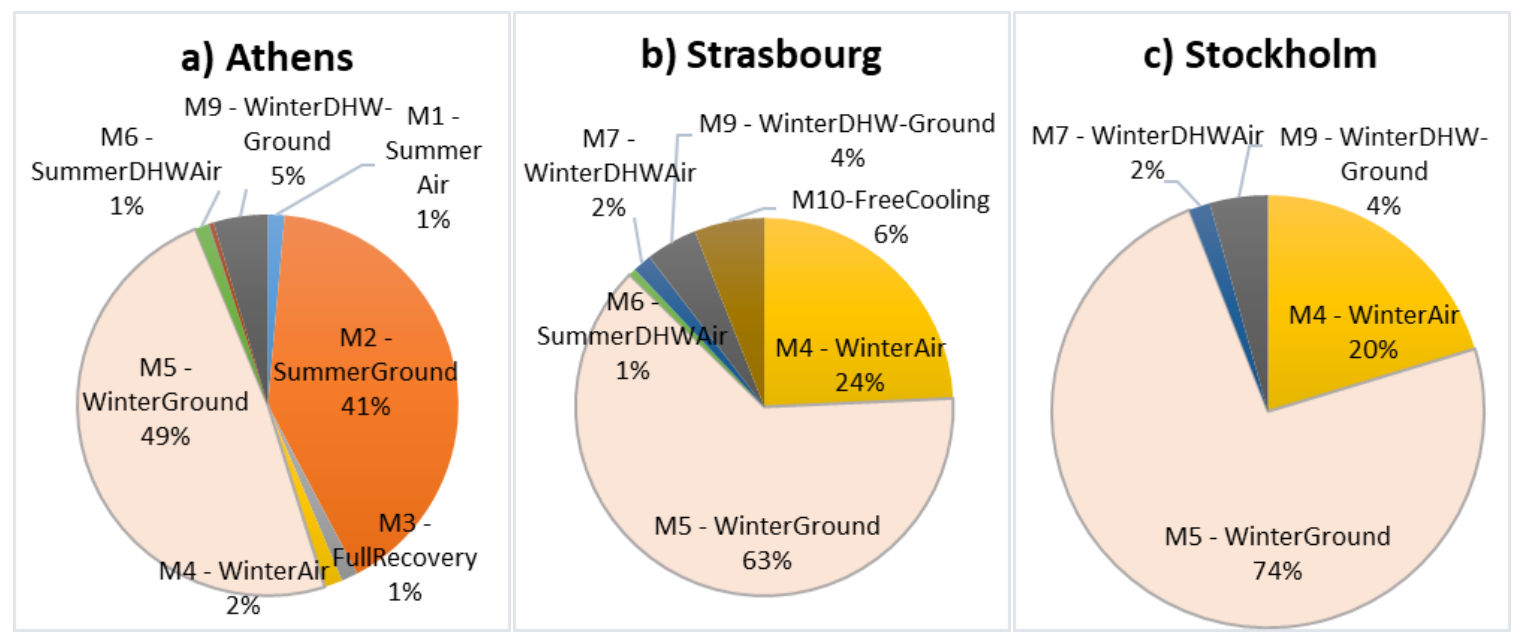

Figure 2 Percentage of the thermal energy provided by the heat pump in the different operating modes for each location: a) Athens; b) Strasbourg; c) Stockholm.

Table 4. Total energy and fluid return temperature from the ground

\begin{tabular}{cccc}
\hline Location & Athens & Strasbourg & Stockholm \\
\hline \hline Total building climate conditioning / DHW energy $(\mathrm{kWh})$ & $7344 / 488$ & $8913 / 634$ & $12243 / 772$ \\
Maximum/Minimum/Average return temperature from the ground $\left({ }^{\circ} \mathrm{C}\right)$ & $25.1 / 10.3 / 17.8$ & $15.1 /(-4.4) / 6.6$ & $10.6 /(-3.8) / 3.5$ \\
\hline
\end{tabular}

It can be seen in Table 4 that the energy provided to the user for the building climate conditioning of the building by the heat pump and free-cooling heat exchanger is around a 7\% higher than the yearly thermal demand shown in Table 2. This difference is due to the thermal losses in the pipes and the buffer tank. Regarding the DHW energy provided by the heat pump, it is higher in the colder locations, mainly due the colder water coming from the net to the tank. In Table 4 it is also possible to see the influence of the ground properties in the fluid temperature coming from the ground, the minimum return temperature is lower in Strasbourg $\left(-4.4^{\circ} \mathrm{C}\right)$ than in Stockholm $\left(-3.8^{\circ} \mathrm{C}\right)$, despite the fact that Stockholm has a colder climate. This is due to the low ground thermal conductivity in Strasbourg $(1 \mathrm{~W} /(\mathrm{m} \cdot \mathrm{K}))$, which makes the local ground temperature decrease to a higher degree due to a lower heat transfer effectiveness in the ground source heat exchanger. Regarding the SPF4, it was calculated for each location and it is shown in Figure 3.

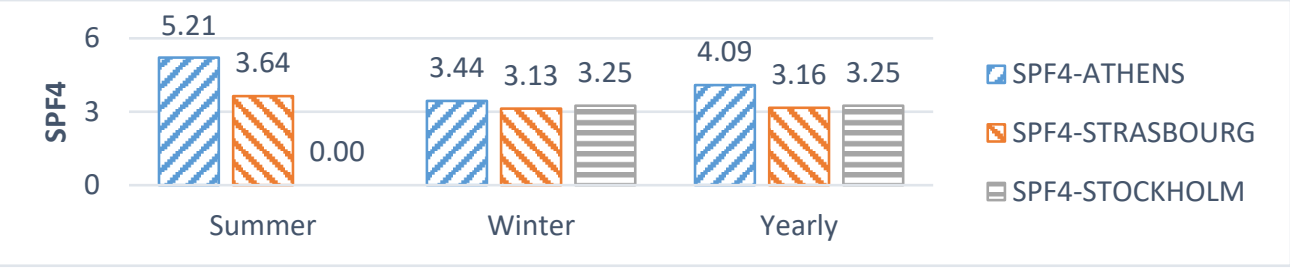

Figure 3 System Seasonal Performance Factor (SPF4) for the three locations 
As shown in Figure 3, SPF4 values are rather low compared to standard GSHP systems already existing in the market. This is mainly because the DSHP considered in this study, is still a prototype that works with an innovative refrigerant (R32) for which the compressor available in the market is not optimized yet, leading to a lower performance.

As described in (Corberán, et al. 2018), the DSHP prototype has a better performance in cooling mode than in heating mode (up to $40 \%$ better SPF4 in the case of Amsterdam). In the case of Athens, the SPF4 in summer operating conditions shown in Figure 3 is around a 50\% higher than that of winter conditions. Regarding the performance during the summer season in Strasbourg, the heat pump system provides air conditioning only by free-cooling, but also produces a higher fraction of DHW, leading to a lower summer SPF4. Concerning the SPF4 in winter, it is higher in Athens (3.4), mainly due to the use of the ground as a source and the higher return temperature from the ground than in the other locations. In Strasbourg and Stockholm, the SPF4 is quite similar, due to the fact that their operating mode share (M4/M5) is similar and the return temperatures from the ground are also similar. Taking a look at the results, it could be concluded that the higher the number of hours that the system runs in heating mode and for DHW production, the more similar will be the yearly SPF4 to the one corresponding to winter conditions. As the heat pump performance is less efficient in heating mode than in cooling mode, the SPF4 will be lower for heating dominated areas. Given that Athens is the location with a higher cooling demand, it is expected that the yearly SPF4 is the largest as shown in Figure 3. Regarding the dual source concept, it is concluded that the use of a DSHP is not recommended for warmer locations like Athens, where the heat pump works most of the time using the ground, as it is a more favourable source/sink. However, in colder locations like Strasbourg or Stockholm, the air is used for more than $20 \%$ of the energy production, so the use of a DSHP could lead to a reduction in the BHEs size and then, a lower investment.

\section{CONCLUSION}

An energy assessment of a dual source heat pump (DSHP) system was carried out with the help of an integrated system model in TRNSYS for the same type of building located at three different locations in Europe: Athens (warm climate), Strasbourg (average climate) and Stockholm (cold climate). The studied DSHP was developed in the GEOTeCH European project with the aim of selecting the most favorable source/sink (air or ground) depending on their temperatures and leading to a reduction in the size of the BHE field needed with a consequent reduction in the initial cost of the installation. A yearly simulation of the system operation was carried out in TRNSYS for each location and the main performance indicators were calculated. It was concluded that the higher the running hours in heating mode and for DHW production, the lower the yearly performance factor (SPF4) of the system. Therefore, the SPF4 will be lower for heating dominated areas. Given that Athens is the location with a higher cooling demand, the yearly SPF4 obtained was the largest taking values up to $25 \%$ larger than that of the other heating dominated areas like Strasbourg and Stockholm. Regarding the use of the air or ground as a source, it was concluded that the use of a DSHP is not recommended for cooling dominated areas like Athens (warm climate), as the air is only used to provide a $4 \%$ of the total thermal energy demand. On the other hand, in the case of Strasbourg and Stockholm (average and cold climate), the air is used as a source to provide more than $20 \%$ of the thermal energy demand. Therefore, the use of a DSHP will be an attractive alternative compared to a standard ground source heat pump in this type of climatic conditions (average and cold climate), as it would allow taking advantage of the two sources, leading to a smaller size of the BHE field needed and a consequent lower investment.

\section{ACKNOWLEDGMENTS}

The present work has been supported by the European Community Horizon 2020 Program for European Research and Technological Development (2014-2020) inside the framework of the project 656889 - GEOTeCH (Geothermal Technology for Economic Cooling and Heating), by the Generalitat Valenciana inside the program "Ayudas para la contratación de personal investigador en formación de carácter predoctoral (ACIF/2016/131)" and by the Ministerio de Educación, Cultura y Derporte inside the program "Formación de Profesorado Universitario (FPU15/03476)". 


\section{REFERENCES}

Corberán JM, Cazorla A, Marchante J, Montagud C and Masip X. 2017. Modelling and energy analysis of a dual source heat pump system in an office building. 16th International Conference on Sustainable Energy Technologies - SET 2017. Bologna, Italy. July 17-20.

Corberán, J. M., Cazorla-Marin A., Marchante-Avellaneda, J. and Montagud, C. 2018. Dual Source Heat Pump, a High Efficiency and Cost-Effective Alternative for Heating, Cooling and DHW Production. International Journal of Low-Carbon Technologies. Available online at: https://doi.org/10.1093/ijlct/cty008.

European Commision. 2003. GeoCool (Geothermal Heat Pump for Cooling and Heating along European Coastal Areas) (EU 5th Framework Programme, NNE5-2001-00847). Available online at: http://cordis.europa.eu/project/rcn/86940_en.html.

European Commision. 2009. GROUND-MED (Advanced Ground Source Heat Pump Systems for Heating and Cooling in Mediterranean climate) (TREN/FP7EN/218895). Available online at: http://groundmed.eu/.

European Commision. 2015. GEOTeCH (Geothermal Technology for €conomic Cooling and Heating) (H2020-LCE-20142, GEOTeCH-656889). Available online at: http://www.geotech-project.eu/.

European Technology Platform on Renewable Heating and Cooling. 2013. Strategic Research and Innovation Agenda for Renewable Heating \& Cooling. Secretariat of the RHC-Platform, Brussels.

IEA. 2011. Technology Roadmap: Energy-Efficient Buildings: Heating and Cooling Equipment. Technical report. Paris, France. IEA Publications.

IEE. 2009a. TABULA (Typology Approach for Building Stock Energy Assessment). Available online at: http://episcope.eu/iee-project/tabula/.

IEE. 2009b. SEPEMO-Build (SEasonal PErformance Factor and MOnitoring for Heat Pump Systems in the Building Sector). (IEE/08/776/SI2.529222). Available online at: http://sepemo.ehpa.org/.

Meteotest. 1981. Meteonorm. Available online at: http://www.meteonorm.com.

Ruiz-Calvo, F., Montagud, C., Cazorla-Marín, A. and Corberán, J.M. 2017. Development and Experimental V alidation of a TRNSYS Dynamic Tool for Design and Energy Optimization of Ground Source Heat Pump Systems. Energies 10: 1510.

Tinti, F., Kasmaee, S., Elkarmoty, M., Bonduà, S. and Bortolotti, V. 2018. Suitability Evaluation of Specific Shallow Geothermal Technologies Using a GIS-Based Multi Criteria Decision Analysis Implementing the Analytic Hierarchic Process. Energies 11(2): 457478. Available online at: http://www.mdpi.com/1996-1073/11/2/457. 